\title{
AUDITORIA DE SEGURANÇA E SAÚDE DO TRABALHO EM UMA INDÚSTRIA DE ALIMENTOS DO ESTADO DO PARANÁ
}

\section{SAFETY AND WORK HEALTH: AUDIT AT A FOOD INDUSTRY OF PARANÁ STATE}

\author{
Tainara Rigotti de Castro*E-mail: tainararcastro@hotmail.com \\ Cristhiane Passos Okawa** E-mail: crisokawa@gmail.com \\ *Universidade Estadual do Paraná, Campus Campo Mourão (UNESPAR), Campo Mourão, PR \\ **Universidade Estadual de Maringá, Campus de Maringá (UEM), Maringá, PR
}

\begin{abstract}
Resumo: Esta pesquisa teve por objetivo avaliar as condições de segurança e saúde no trabalho em uma indústria alimentícia do ramo de atividades de produção de biscoitos e salgadinhos para aperitivo. Por meio de inspeções, entrevistas informais com supervisores e funcionários, foram identificados os riscos para análise da saúde e segurança do trabalho por meio da aplicação de um checklist para verificação das não conformidades presentes no local, com base nas Normas Regulamentadoras (NRs). A indústria apresentou necessidade de implantação de Serviços Especializados em Engenharia de Segurança e em Medicina do Trabalho (SESMT) e Programa de Controle Médico e Saúde Ocupacional (PCMSO), revisão da Comissão Interna de Prevenção de Acidentes (CIPA), adoção de Equipamentos de Proteção Individual (EPIs), elaboração do Programa de Prevenção de Riscos Ambientais (PPRA), implantação de sinalização de segurança e da segurança do trabalho em máquinas, necessidade de compra de equipamentos, adoção de medidas na área de ergonomia, entre outros.
\end{abstract}

Palavras-chave: Riscos na produção de biscoitos. Riscos na Produção de salgadinhos. Segurança na indústria alimentícia. Checklist.

\begin{abstract}
This paper aimed to valuate the safety and health conditions at work and propose improvements in a food industry producing biscuits and snacks for appetizer. Through inspections, interviews with supervisors and employees were identified risks to occupational health and safety through the application of a checklist for verification of non conformances present on the place, based on Regulatory Standards (NRs). The industry presented a need for the deployment of Services Specialized in Safety Engineering and Occupational Medicine (SESMT) and Medical Control Program and Occupational Health (PCMSO), review of Internal Commission for Accident Prevention (CIPA), adoption of Personal Protective Equipment (EPI), preparation of the Environmental Risk Prevention Program (PPRA), implementation of safety signs and of work safety on machines, need to purchase equipment, adoption of measures in the area of ergonomics, among others.
\end{abstract}

Keywords: Risks in the production of biscuits. Risks in the production of snacks. Safety in the food industry. Checklist.

\section{INTRODUÇÃO}

A saúde e o trabalho estão permeados pelas grandes transformações societárias e suas contradições contemporâneas, relacionadas fundamentalmente aos processos de gestão e organização do trabalho, viabilizados em especial pelas 
novas tecnologias, impactando na saúde dos trabalhadores (MENDES; WUNSCH, 2007).

Entretanto, as novas tecnologias dividem espaço com os sistemas produtivos antigos e ultrapassados. Na indústria alimentícia brasileira, por exemplo, considerada um ícone mundial, há uma grande congregação de grandes multinacionais e nacionais que operam neste setor. Todavia, também existem empresas menos avançadas, gerenciadas e movimentadas por grupos familiares, com produção artesanal e distribuição restrita.

Neste setor, a política competitiva adotada pelo Brasil está ligada a políticas de produtividade e competitividade, fazendo com que os trabalhadores deste ramo acabem sofrendo os desgastes e os esforços regidos pela execução de tarefas repetitivas, acompanhadas de ruído, equipamentos perigosos, esforço físico, entre outras exigências as quais o trabalho os submete.

Para oferecer segurança a tais trabalhadores, a legislação brasileira profere que o empregador deve garantir que o ambiente de trabalho seja projetado de tal forma que minimize os riscos à saúde e segurança de seu empregado, visto que é de direito desses, a redução dos riscos inerentes ao trabalho, por meio de normas de saúde, higiene e segurança (BRASIL, 1998).

Mesmo com a existência das legislações brasileiras, de acordo com Lacerda et al. (2005), os índices de acidentes do trabalho ainda são altos e geralmente decorrentes das más condições e da insegurança dos ambientes de trabalho aliadas à falta de fiscalização por parte dos órgãos competentes. O cumprimento das Normas Regulamentadoras do Ministério do Trabalho e Emprego (NRs) é um desafio para a maioria das empresas que, em geral, priorizam as melhorias da qualidade do produto ao invés de melhores condições ambientais de trabalho.

Entretanto, a Portaria $\mathrm{n}^{\circ}$ 326/97, que dispõe a regulamentação de alimentos (BRASIL, 1997), deixa claro a obrigatoriedade da importância não somente da qualidade do produto, mas também do conforto e segurança do ambiente de trabalho. Sendo assim, a empresa, ao atender às necessidades de bem-estar de seus colaboradores, diminui seus custos operacionais, aumentando a produtividade, os lucros e a qualidade dos produtos, fatores fundamentais em meio ao mercado competitivo. 
Diante desse contexto, definiram-se como objeto de estudo, os fatores de riscos ocupacionais do trabalho em uma indústria alimentícia, do ramo de atividades de produção de biscoitos e de salgadinhos para aperitivo. Como objetivo, buscou-se identificar os fatores de risco nos diferentes setores de trabalho, em relação ao local, aos equipamentos, às substâncias e aos materiais, fatores ergonômicos e fatores organizacionais.

\section{ACIDENTES DE TRABALHO}

O Ministério da Previdência Social (2012) define acidente do trabalho como aquele que ocorre pelo exercício do trabalho a serviço da empresa ou pelo exercício do trabalho dos segurados especiais, provocando lesão corporal ou perturbação funcional, permanente ou temporária, que cause a morte, a perda ou a redução da capacidade para o trabalho. Equiparam-se também ao acidente do trabalho: 0 acidente ligado ao trabalho que, embora não tenha sido a causa única, haja contribuído diretamente para a ocorrência da lesão; certos acidentes sofridos pelo colaborador no local e no horário de trabalho; a doença proveniente de contaminação acidental do empregado no exercício de sua atividade; e o acidente sofrido a serviço da empresa ou no trajeto entre a residência e o local de trabalho.

Durante o ano de 2012, foram registrados no Instituto Nacional do Seguro Social (INSS), segundo dados do Anuário Estatístico de Acidentes do Trabalho (AEAT) do Ministério da Previdência Social (2012), cerca de 705,2 mil acidentes do trabalho. Deste montante, 978 ocorreram na indústria de fabricação de biscoitos e bolachas. Em relação à categoria de salgadinhos para aperitivo, esta está inserida dentro da classe de produtos alimentares não especificados pelo Ministério da Previdência Social, ou seja, nesta classe existe a inserção de outros tipos de produtos, sendo registrado um total de 2.118 acidentes do trabalho no ano de 2012 .

Carpes Jr. e Sell (2003) realizaram um estudo sobre as várias teorias de acidentes de trabalho, onde observaram que elas evoluíram de uma visão em que o trabalhador era sempre o culpado pelo acidente, até uma que admite a coexistência de diversas causas para os mesmos.

No Brasil, é prática corrente das empresas atribuírem a ocorrência do acidente de trabalho a comportamentos inadequados do trabalhador (descuido, imprudência, negligência, desatenção), em que as investigações de acidentes 
trabalhistas somente se concentram para recomendações centradas na mudança de comportamento do colaborador (prestar mais atenção, tomar mais cuidado, reforçar o treinamento).

Entretanto, de acordo com a Previdência Social (2012), mais da metade do total de acidentes registrados no ano de 2012 (423.935 acidentes), ocorreram por motivos típicos, decorrentes principalmente da característica da atividade profissional desempenhada pelo acidentado. As doenças do trabalho também apresentam relevância pelo impacto que causam à saúde do trabalhador.

De forma geral, não é possível eliminar o risco de acidentes, porém é possível a prevenção através da eliminação de suas causas, que podem decorrer tanto das condições pessoais dos colaboradores quanto das condições existentes no local de trabalho.

Para Quelhas, Alves e Filardo (2003), os aspectos preventivos envolvidos na segurança do trabalho buscam minimizar os riscos e as condições inadequadas e incorporar a melhoria contínua das condições de trabalho introduzindo requisitos mínimos de segurança cada vez mais rígidos. Os riscos de acidentes podem ser identificados pela inspeção sistemática do local de trabalho, sendo esta uma das medidas preventivas mais importantes para assegurar um local de trabalho seguro.

\subsection{Acidentes Ocupacionais}

Os riscos estão presentes nas mais diversas situações, especialmente nos ambientes de trabalho. De acordo com Rodrigues et al. (2008), atualmente, os trabalhadores estão mais sujeitos a acidentes ocupacionais provocados pela pressão que estão submetidos, principalmente os que desenvolvem funções nas indústrias de alimentos, cujas atividades demandam cuidados acentuados em relação ao controle dos produtos, o que pode acarretar-lhes desgastes emocionais, físicos e psicológicos. Tais fatores podem influenciar diretamente no ritmo da produção, seja pela incidência de doenças ocupacionais ou ainda, pela ocorrência de acidentes.

Os riscos ocupacionais são aqueles que podem causar danos à saúde do trabalhador em seu ambiente de trabalho. Podem ser classificados segundo sua 
natureza e a forma com que atuam no organismo humano, conforme disposto no Quadro 1, de acordo com a Norma Regulamentadora 5 (NR-5) (BRASIL, 1999).

Quadro 1 - Classificação dos principais riscos ocupacionais

\begin{tabular}{|c|c|c|c|c|}
\hline $\begin{array}{l}\text { Riscos } \\
\text { físicos }\end{array}$ & $\begin{array}{c}\text { Riscos } \\
\text { químicos }\end{array}$ & $\begin{array}{c}\text { Riscos } \\
\text { biológicos }\end{array}$ & Riscos ergonômicos & Riscos de acidentes \\
\hline Ruídos & Poeiras & Vírus & Esforço físico intenso & Arranjo físico inadequado \\
\hline Vibrações & Fumos & Bactérias & $\begin{array}{l}\text { Levantamento } \\
\text { transporte manual de peso }\end{array}$ & $\begin{array}{l}\text { Máquinas e equipamentos } \\
\text { sem proteção }\end{array}$ \\
\hline $\begin{array}{l}\text { Radiações } \\
\text { ionizantes }\end{array}$ & Névoas & Protozoários & $\begin{array}{l}\text { Exigência de postura } \\
\text { inadequada }\end{array}$ & $\begin{array}{l}\text { Ferramentas inadequadas } \\
\text { ou defeituosas }\end{array}$ \\
\hline $\begin{array}{l}\text { Radiações } \\
\text { não } \\
\text { ionizantes }\end{array}$ & Neblinas & Fungos & $\begin{array}{l}\text { Controle rígido de } \\
\text { produtividade }\end{array}$ & Iluminação inadequada \\
\hline Frio & Gases & Parasitas & $\begin{array}{lll}\text { Imposição } & \text { de } & \text { ritmos } \\
\text { excessivos } & & \\
\end{array}$ & Eletricidade \\
\hline Calor & Vapores & Bacilos & $\begin{array}{l}\text { Trabalho em turno e } \\
\text { noturno }\end{array}$ & $\begin{array}{l}\text { Probabilidade de incêndio } \\
\text { ou explosão }\end{array}$ \\
\hline $\begin{array}{l}\text { Pressões } \\
\text { anormais }\end{array}$ & $\begin{array}{l}\text { Substâncias, } \\
\text { compostas ou } \\
\text { produtos químicos }\end{array}$ & & $\begin{array}{l}\text { Jornada de trabalho } \\
\text { prolongada }\end{array}$ & $\begin{array}{l}\text { Armazenamento } \\
\text { inadequado }\end{array}$ \\
\hline Umidade & & & Monotonia e repetitividade & Animais peçonhentos \\
\hline & & & $\begin{array}{lr}\text { Outras situações } \\
\text { causadoras de } \\
\text { físico e/ou psíquico }\end{array}$ & $\begin{array}{l}\text { Outras situações de risco } \\
\text { que poderão contribuir } \\
\text { para a ocorrência de } \\
\text { acidentes }\end{array}$ \\
\hline
\end{tabular}

Fonte: Brasil (1999)

\subsubsection{Riscos físicos}

De acordo com a NR-9 (BRASIL, 1994) consideram-se agentes físicos as diversas formas de energia a que possam estar expostos os trabalhadores, tais como ruídos, vibrações, pressões anormais, temperaturas extremas, radiações ionizantes, radiações não ionizantes, bem como o infrassom e o ultrassom.

As máquinas e equipamentos utilizados pelas empresas produzem ruídos que podem atingir níveis excessivos. Sua intensidade é medida em decibéis $(\mathrm{dB})$, podendo causar danos imediatos ou graduais aos que a eles se expõem por tempo e níveis acima do recomendado. A NR-15 (BRASIL, 1978) relata que existem dois tipos de ruídos, sendo eles: o contínuo ou intermitente e o de impacto. $O$ anexo $n^{\circ} 1$ desta Norma traz os limites de tolerância para o primeiro caso.

É comum, em indústrias, o uso de máquinas e equipamentos que produzem vibrações, as quais podem ser nocivas ao trabalhador. Essas podem ser localizadas ou de corpo inteiro. Esse risco é considerado insalubre caso o trabalhador exposto Revista Produção Online, Florianópolis, SC, v. 16, n. 2, p. 678-704, abr./jun. 2016. 
esteja sem a proteção adequada e é regulamentado pelo anexo $n^{\circ} 8$ da NR-15 (BRASIL, 1978).

Há uma série de atividades em que os trabalhadores ficam sujeitos a pressões ambientais acima ou abaixo das pressões normais. Por sua vez, as pressões anormais, ocorrem em trabalhos sob ar comprimido e dos trabalhos submersos, onde o trabalhador é obrigado a suportar pressões maiores que a atmosférica, exigindo-se descompressão. O anexo $n^{\circ} 6$ da NR-15 (BRASIL, 1978) traz regulamentações e recomendações a cerca desses tipos de tarefas.

As temperaturas extremas (frio e calor) podem causar danos à saúde do trabalhador. No caso de exposição excessiva ao calor, os limites são os constantes do anexo no 3 da NR-15 (BRASIL, 1978). Em geral, é necessário a implementação de procedimentos para uma adequada reidratação, além de vestimentas adequadas. Em relação à exposição excessiva ao frio, disposta pelo anexo $n^{\circ} 9$ da NR-15 (BRASIL, 1978), como por exemplo as câmaras frias, em torno de temperaturas por volta de $-1^{\circ} \mathrm{C}$, já se começa a ocorrer o congelamento dos tecidos.

A absorção de radiações pelo organismo é responsável pelo aparecimento de diversas lesões, podendo ser classificadas como ionizantes ou não ionizantes. $O$ anexo $n^{\circ} 5$ da NR-15 (BRASIL, 1978) ressalta que nas atividades ou operações onde trabalhadores possam ser expostos a radiações ionizantes, como os Raios-X, por exemplo, os limites de tolerância, princípios, obrigações, entre outros, estão dispostos na Norma CNEN-NE-3.01 (Diretrizes Básicas de Radioproteção). Já as radiações não ionizantes, regulamentada pelo anexo $\mathrm{n}^{\circ} 7$ da mesma Norma, como as microondas, ultravioleta e laser, são consideradas insalubres, caso não ofereçam proteção adequada.

\subsubsection{Riscos químicos}

De acordo com a NR-9 (BRASIL, 1994), consideram-se agentes químicos as substâncias, compostos ou produtos que possam penetrar no organismo pela via respiratória, nas formas de poeiras, fumos, névoas, neblinas, gases ou vapores, ou que pela natureza da atividade de exposição, possam ter contato ou ser absorvidos pelo organismo através da pele ou por ingestão. 


\subsubsection{Riscos biológicos}

Os riscos biológicos relacionam-se à capacidade de organismos vivos causarem doenças no organismo humano. De acordo com a NR-9 (BRASIL, 1994), consideram-se agentes biológicos as bactérias, fungos, bacilos, parasitas, protozoários, vírus, entre outros.

Esses organismos estão presentes em muitos ambientes de trabalho e desencadeiam muitas doenças, principalmente aos que trabalham na agricultura, construção civil, veterinária e nos serviços de assistência à saúde.

\subsubsection{Riscos ergonômicos}

A ergonomia é tratada pela Norma Regulamentadora 17 do Ministério do Trabalho (BRASIL, 1990). Esta norma tem por finalidade estabelecer parâmetros que permitam adaptar as condições de trabalho às características psicofisiológicas dos trabalhadores, de modo a proporcionar o máximo de conforto, segurança de desempenho eficiente.

Menezes e Santos (2014) enfatizam que o objetivo da ergonomia é adaptar o trabalho ao homem, se interessando em compreender o distanciamento entre 0 prescrito e a realidade, visto que a não adequação pode provocar diminuição do desempenho dos trabalhadores, havendo a importância da adaptação do trabalho, no que diz respeito às máquinas equipamentos e ambiente, ao homem, às características e restrições, valores e limitações.

Muitas situações do trabalho e também da vida cotidiana são prejudiciais a saúde. As posturas desfavoráveis no ambiente de trabalho podem conduzir ao desenvolvimento de Lesões por Esforço Repetitivo (LER) e Doenças Osteomusculares Relacionadas com o Trabalho (DORT), seja através de trabalho estático ou de posturas assumidas durante um trabalho mais dinâmico.

A NR-17 (BRASIL, 1990) coloca em seu item 17.1.2 que para avaliar a adaptação das condições de trabalho às características psicofisiológicas dos trabalhadores, cabe ao empregador realizar a análise ergonômica do trabalho. Desta forma, há uma exigência normativa para que a análise ergonômica do trabalho seja 
realizada pelo empregador. A análise das condições de trabalho é um elemento essencial para o desenvolvimento da ergonomia no ambiente de trabalho.

De forma geral, pode-se considerar que avaliar a ergonomia no ambiente de trabalho não é mais do que um exame cuidadoso, realizado a fim de detectar os componentes que lá existem, capazes de causar danos aos colaboradores expostos.

\subsubsection{Riscos de acidentes}

Os riscos de acidentes se originam das atividades que envolvem máquinas e equipamentos, sendo responsáveis pelo surgimento das lesões. Esses acidentes ocorrem pelo fato das máquinas e equipamentos não possuírem proteção, ferramentas defeituosas ou inadequadas.

Para tal, a NR-12 (BRASIL, 2010) define referências técnicas, princípios fundamentais e medidas de proteção para garantir a saúde e a integridade física dos trabalhadores e estabelece requisitos mínimos para a prevenção de acidentes e doenças do trabalho nas fases de projeto de utilização de maquinas e equipamentos de todos os tipos.

E imprescindível que o empregador adote medidas de proteção para o trabalho em maquinas e equipamentos, a fim de garantir a saúde e a integridade física dos trabalhadores e medidas apropriadas sempre que houver pessoas com deficiência envolvidas direta ou indiretamente no trabalho.

Os riscos de acidentes ainda englobam a iluminação inadequada. A NR-17 (BRASIL, 1990) ressalta que os locais de trabalho devem possuir iluminação adequada, natural ou artificial, sendo apropriada a natureza dos trabalhos. Ambientes com excesso ou falta de iluminação dificultam o trabalho, além de contribuírem para o aumento dos acidentes. Os níveis mínimos de iluminância de interiores se utiliza a Norma ABNT NBR ISO/CIE 8995-1:2013, que estabelece os valores de iluminância no ambiente de trabalho.

Este estudo teve por objetivo a verificação das condições de trabalho, sobretudo dos riscos ocupacionais, envolvidos em uma indústria de alimentos, classificada conforme a Classificação Brasileira de Ocupações (CBO) (BRASIL, 2002) como sendo do ramo de atividades de fabricação de biscoitos e bolachas, por 
produzir biscoitos e bolachas e também do ramo de atividades de fabricação de outros produtos alimentícios, por produzir salgadinhos para aperitivo.

\section{METODOLOGIA}

A presente pesquisa foi realizada no mês de outubro do ano de 2014. A indústria alimentícia, neste momento, estava presente no mercado há 12 anos e contava com um efetivo fixo de 104 colaboradores, sendo 39 pessoas na área de administração; 18 pessoas na área de transportes e 47 pessoas envolvidas diretamente com a produção dos alimentos. Por restrições da própria indústria, a mesma será aqui denominada como Empresa X.

As condições de trabalho, bem como as não conformidades dos processos e instalações, foram avaliadas através da aplicação de um checklist, tendo por base as normatizações pertinentes ao local avaliado.

A metodologia empregada consistiu em realizar a descrição dos processos de trabalho; o exame das normatizações pertinentes; a elaboração de um checklist de verificação para avaliação das não conformidades encontradas e por fim, a realização de inspeções nos locais de trabalho.

\section{RESULTADOS}

\subsection{Processo Produtivo}

A Empresa $X$ possui duas marcas de alimentos: uma consiste na fabricação de biscoitos e a outra na fabricação de salgadinhos para aperitivo. A produção de bolachas possui uma linha de produção para a fabricação de rosquinhas e biscoitos de leite. A produção dos salgadinhos para aperitivo possui duas linhas de produção: uma fabrica salgadinhos de milho extrusado e a outra, pasteizinhos de trigo.

\subsubsection{Fabricação de biscoitos}

$\mathrm{Na}$ linha de produção da fabricação de biscoitos, a indústria possui 12 colaboradores. O processo de fabricação dos biscoitos, disposto na Figura 1, se inicia com o transporte da matéria-prima à sala de preparo da massa, onde os 
ingredientes são conferidos, pesados e misturados. É feita a formatação, distribuição automática da massa e assadura com o auxílio de esteiras. Os biscoitos são resfriados em temperatura ambiente e empacotados automaticamente. Posteriormente são embalados em caixas e estocados, para posterior expedição.

Figura 1 - Fluxograma do processo de produção de biscoitos

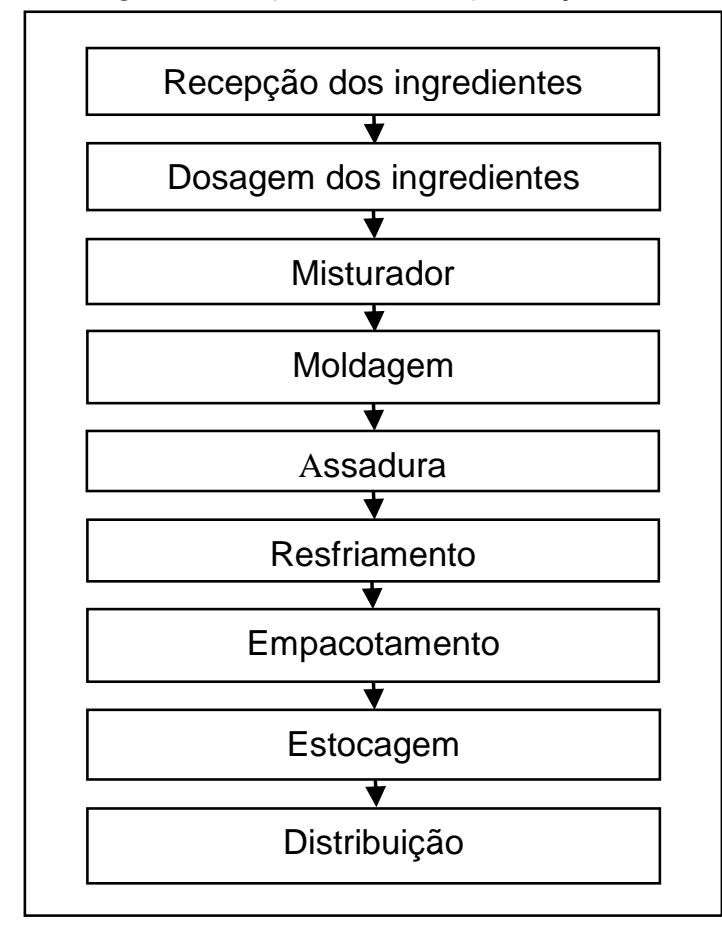

\subsubsection{Fabricação de salgadinhos de milho extrusado}

A produção dos salgadinhos de milho extrusado conta com 25 colaboradores, O processo se inicia, conforme indicado na Figura 2, quando os ingredientes são misturados através da máquina extrusora, onde são formatados e enviados ao secador rotativo para serem saborizados e aromatizados. Os salgadinhos são ensacados em sacos de aproximadamente $12 \mathrm{~kg}$ e posteriormente armazenados. Conforme a necessidade, esses sacos são encaminhados à área de empacotamento. Após empacotados os salgadinhos são embalados em fardos, estocados e expedidos. 
Figura 2 - Fluxograma do processo de produção de salgadinhos de milho extrusado

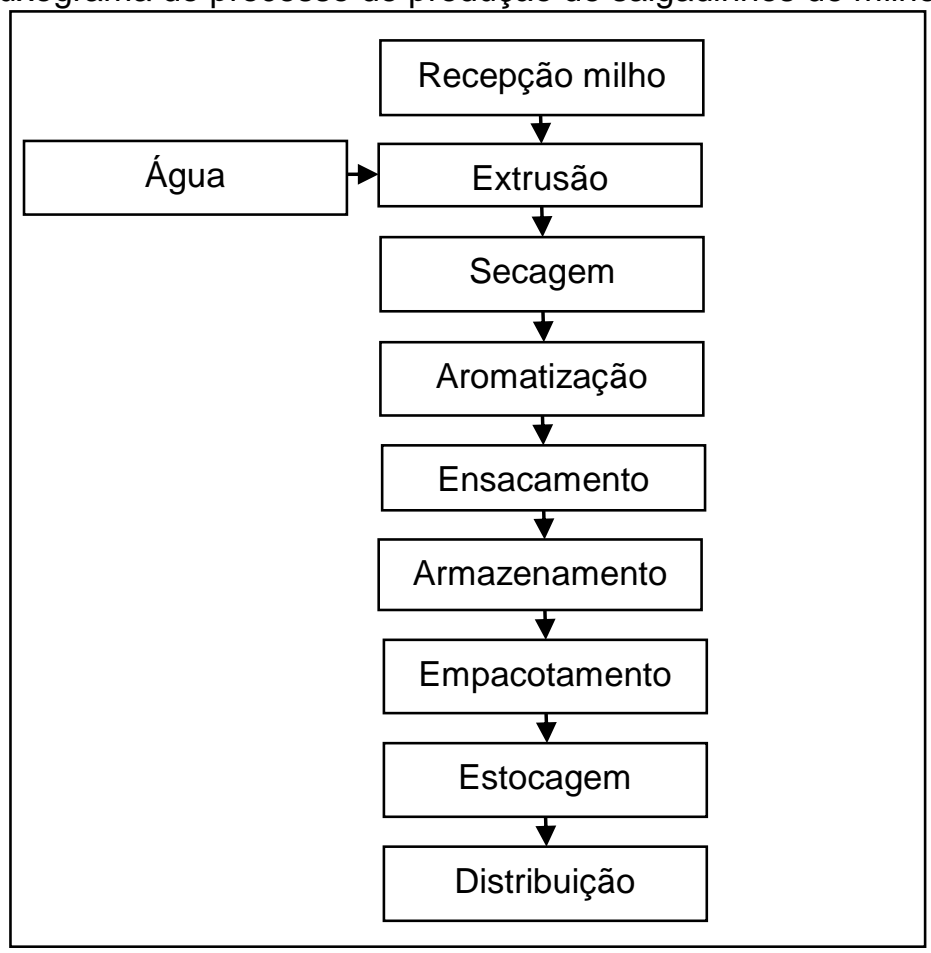

\subsubsection{Fabricação de pasteizinhos de trigo}

O processo de produção dos pasteizinhos de trigo possui 10 colaboradores. Este se inicia com o transporte da matéria-prima à sala de preparo da massa onde os ingredientes são conferidos, pesados e misturados, conforme ilustrado na Figura 3. Após descanso da massa, é realizada a formatação com cilindros e cortadores automáticos. Os pasteizinhos são levados à fritura através de esteiras rolantes, após são saborizados e aromatizados. Os salgadinhos são ensacados em sacos de aproximadamente $10 \mathrm{~kg}$ e posteriormente armazenados. Conforme a necessidade, esses sacos são encaminhados à área de empacotamento. Após empacotados os salgadinhos são embalados em caixas, estocados, para posterior expedição. 
Figura 3 - Fluxograma do processo de produção dos pasteizinhos de trigo

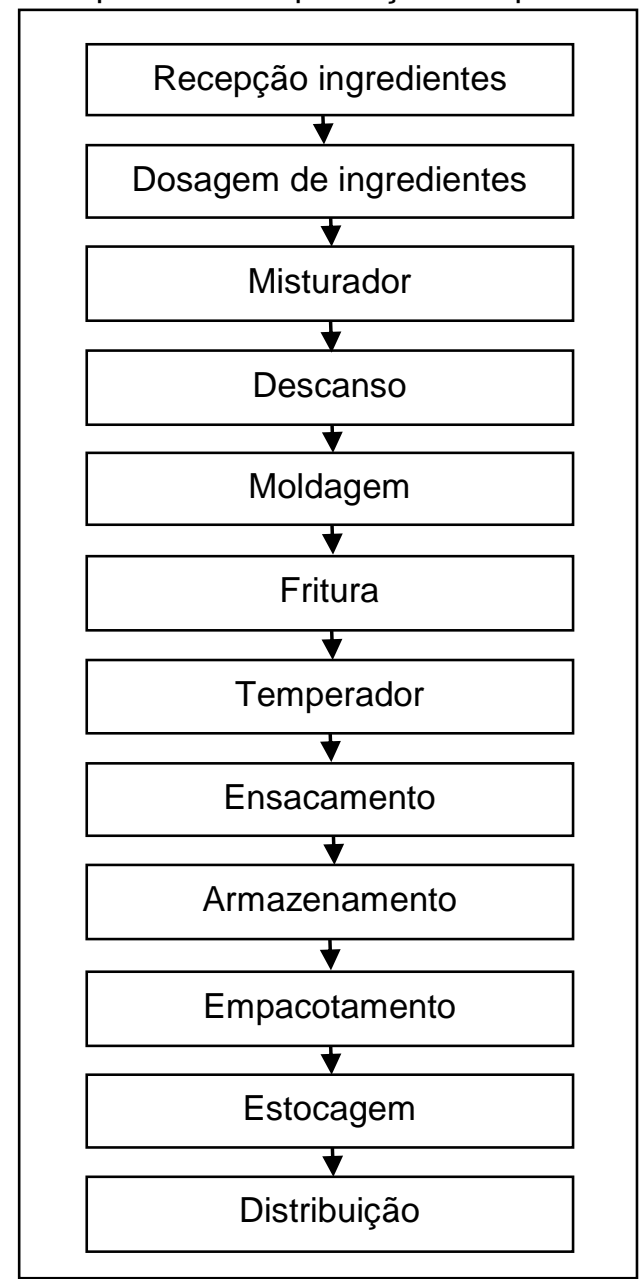

\subsection{Normas Regulamentadoras Aplicáveis}

O Quadro 2 dispõe do apanhado das normas regulamentadoras aplicáveis às diversas atividades desempenhadas pela Empresa X. Desta forma, foram descriminadas e organizadas no checklist disposto em Apêndice. 
Quadro 2 - Normas regulamentadoras aplicáveis

\begin{tabular}{|c|l|}
\hline Norma & Título \\
\hline 4 & $\begin{array}{l}\text { Serviços Especializados em Engenharia de Segurança e em Medicina do Trabalho - } \\
\text { SESMT }\end{array}$ \\
\hline 5 & Comissão Interna de Prevenção de Acidentes - CIPA \\
\hline 6 & Equipamento de Proteção Individual - EPI \\
\hline 7 & Programa de Controle Médico de Saúde Ocupacional - PCMSO \\
\hline 8 & Edificações \\
\hline 9 & Programa de Prevenção de Riscos Ambientais - PPRA \\
\hline 12 & Segurança no trabalho em máquinas e equipamentos \\
\hline 14 & Fornos \\
\hline 15 & Atividades e operações insalubres \\
\hline 17 & Ergonomia \\
\hline 23 & Proteção contra incêndios \\
\hline
\end{tabular}

\subsubsection{Serviços Especializados em Engenharia de Segurança e em Medicina do Trabalho - SESMT}

A Empresa $X$ está enquadrada no grau de risco 3 e por possuir entre 101 a 250 empregados está obrigada, de acordo com a NR-4 anexo II (BRASIL, 1983), a manter o SESMT, com o dimensionamento de 1 técnico de segurança do trabalho, a fim de promover a saúde e proteger a integridade do trabalhador no local de trabalho.

\subsubsection{Comissão Interna de Prevenção de Acidentes - CIPA}

Ficou constatado que a Empresa $\mathrm{X}$ possui uma CIPA em funcionamento, cumpre o que é estabelecido pela NR-5 em relação à sua organização, ao seu funcionamento, ao treinamento e ao processo eleitoral.

$O$ dimensionamento da CIPA na Empresa $X$ conta com 3 membros efetivos e 3 membros suplentes, estando de acordo com o dimensionamento exigido pela NR5 (BRASIL, 1999). Esse dimensionamento compõe tanto representantes do empregador como dos empregados.

Porém, esta CIPA foca suas atividades restritamente na Semana Interna de Prevenção de Acidentes (SIPAT), falhando em outras atribuições tais como: o desenvolvimento de um plano de trabalho que possibilite ação preventiva na solução de problemas de segurança; elaboração do mapa de risco; a realização de reuniões 
periódicas para a discussão dos riscos identificados neste plano; verificações no ambiente de trabalho a fim de identificar situações que tragam riscos; o desenvolvimento de discussões e ações conjuntas com o SESMT, entre outras.

\subsubsection{Equipamento de Proteção Individual - EPI}

Todos os colaboradores da Empresa $\mathrm{X}$ possuem protetores auriculares, devido aos altos níveis de ruído presentes em todo o processo. Todos receberam treinamento de uso e conservação assim que os equipamentos the foram entregues e fazem seu uso corretamente. Os colaboradores da área de extrusão de salgadinhos de milho, onde o ruído é mais intenso, possuem protetores do tipo concha e os demais possuem protetores de inserção.

\subsubsection{Programa de Controle Médico de Saúde Ocupacional - PCMSO}

A Empresa X se encontra em desacordo com a NR-7 (BRASIL, 1994), que enquadra dentre às empresas as que têm a obrigatoriedade da elaboração e implementação do PCMSO, visto que possui grau de risco 3 e mais de 10 funcionários e não oferece um médico do trabalho aos seus colaboradores.

\subsubsection{Edificações}

A Empresa $X$ possui os requisitos mínimos que devem possuir as edificações de acordo com a NR-8 (BRASIL, 1983), para que a segurança e conforto dos colaboradores estejam garantidos. Assim sendo, possui pisos nivelados, rampas e escadas fixas em bom estado de conservação, guarda-corpos tem 0,90m de altura no mínimo a contar de nível do piso, além de coberturas com proteção contra chuvas e que evitam insolação excessiva.

\subsubsection{Programa de Prevenção de Riscos Ambientais - PPRA}

Verificou-se que os trabalhadores da Empresa $X$ estão expostos a agentes físicos e químicos, sendo obrigatória a elaboração do PPRA de acordo com a NR-9 (BRASIL, 1994).

Revista Produção Online, Florianópolis, SC, v. 16, n. 2, p. 678-704, abr.jun. 2016. 


\subsubsection{Segurança no trabalho em máquinas e equipamentos}

Observou-se que não existem as necessárias demarcações no chão, nos locais de instalação de máquinas e equipamentos e áreas de circulação, ao longo de todo o processo de produção. No setor de fabricação de biscoitos inexiste uma área específica demarcada de armazenamento para os materiais em utilização no processo produtivo.

As máquinas e equipamentos são muito antigos, desgastados, não possuem sistema de segurança e apresentam defeitos constantemente. O equipamento de moldagem de biscoitos, não oferece quaisquer tipos de proteção fixas ou móveis ou sensores de segurança, bem como qualquer aviso de perigo ou cuidado. Este equipamento não atende aos aspectos ergonômicos descritos na norma, visto que para abastecimento de massa, os trabalhadores são obrigados a subir em caixotes de madeira dispostos no chão.

As áreas de circulação e os espaços em torno de máquinas e equipamentos estão de forma em que o material e os trabalhadores possa se movimentar com segurança, assim como as instalações e dispositivos elétricos estão em bom estado de conservação.

\subsubsection{Fornos}

Diante do observado na Empresa $X$, em relação aos fornos utilizados, podese afirmar que esses oferecem segurança e não implicam no conforto dos trabalhadores segundo a NR-14 (BRASIL, 1983), pois são revestidos com material refratário e dotados de chaminés de modo que haja a livre saída dos gases queimados.

\subsubsection{Atividades e operações insalubres}

Com base na NR-15 (BRASIL, 1978), constatou-se na área de extrusão dos salgadinhos de milho, um elevado ruído contínuo, podendo ser um local insalubre. Nesta pesquisa, não foi realizada a medição do agente e também nunca requerida a terceiros pelo empregador. 
Ressalta-se que os trabalhadores desta área utilizam abafadores de ouvido para a proteção contra tal agente, porém os colaboradores que trabalham na área ao lado (empacotamento de salgadinhos) também estão expostos ao ruído e utilizam protetores de inserção. Esses dois tipos de EPI oferecem diferentes níveis de proteção.

\subsubsection{Ergonomia}

Todo transporte de carga é feito manualmente. Alguns trabalhadores desempenham o transporte manual descontínuo de cargas, enquanto outros, o transporte manual contínuo, podendo comprometer a saúde do colaborador. Não existe treinamento sobre carregamento de peso, o trabalho é realizado em pé durante toda a jornada de trabalho, inexistindo assentos para descanso durante as pausas que seriam necessárias. Existe insuficiência na quantidade de carrinhos de mão necessários para o auxílio no transporte de carga, desta forma muitos colaboradores o fazem sobre os braços e até mesmo sobre as costas.

Colaboradores que desempenham atividades nas linhas de empacotamento e nos setores administrativos passam grande parte do tempo ou a maior parte dele sentados, e não possuem qualquer tipo de adequação que os projete para a realização de determinada atividade. A tarefa dos colaboradores que fazem o empacotamento é monótona, repetitiva e sem pausas, com grau mínimo de dificuldade, mas sem possibilidade de desligamento mental devido à atenção na contagem dos pacotes para a montagem dos fardos.

Os escritórios não possuem altos níveis de ruído, bem como a iluminação nos locais de trabalho são adequadas.

\subsubsection{Proteção contra incêndios}

Tendo em vista a NR-23 (BRASIL, 2011), em relação à proteção contra incêndios, observou a presença de alguns extintores na Empresa $X$, no entanto, quando inspecionados em relação ao seu prazo de recarga, verificou-se que estes eram muito antigos. Dos extintores presentes, todos possuíam a sinalização adequada, porém a passagem se encontrava obstruída por caixas. 
O local possui dispositivo de alarmes para incêndio, saídas suficientes e sinalizadas, de modo que os que se encontrem nesses locais possam abandoná-los com rapidez e segurança

\section{DISCUSSÃO}

Nesta pesquisa foram levantados fatores no ambiente de trabalho da empresa estudada que podem determinar riscos para acidentes, pois podem se constituir situações nas quais, a interação de diversos fatores que transformem situações controladas em não controladas.

Para Heinrich (1959), o acidente seria causado por uma cadeia linear de fatores, como uma sequência de dominós justapostos, que culminaria na lesão. A primeira peça do dominó seria os fatores sociais e ambientais prévios responsáveis pela formação do caráter dos operários. A segunda peça, os comportamentos inadequados dos trabalhadores, frutos de características herdadas ou adquiridas. Esses comportamentos inadequados poderiam vir a constituir-se em atos inseguros, isto é, em comportamentos de risco que, juntamente com a presença de condições inseguras (terceira peça do dominó), levariam à ocorrência do acidente e, por fim, à lesão (respectivamente a quarta e a quinta peças da sequência de dominós).

O SESMT é uma equipe de profissionais, que tem por finalidade promover a saúde e proteger a integridade do trabalhador no local de trabalho. É regulamentado pela NR-4 (BRASIL, 1983), onde seu dimensionamento vincula-se à gradação do risco da atividade principal e ao número total de empregados na empresa. O serviço pode incluir médico do trabalho, enfermeiro do trabalho, técnico de enfermagem do trabalho, engenheiro de segurança do trabalho e/ou técnico de segurança do trabalho.

Ressalta-se a importância do cumprimento legal em relação a compor o SESMT. Cabe à Empresa $X$, para o dimensionamento correto do SESMT, a contratação de um técnico de segurança do trabalho. Magnano et al. (2013) concluiu em sua pesquisa que o desempenho do SESMT é essencial para a redução e eliminação de risco para a saúde dos trabalhadores, especialmente em relação a insalubridade. Os profissionais das equipes de SESMT têm habilidades únicas e essenciais que são necessários para assegurar e desenvolver a assistência médica 
para os trabalhadores, principalmente aqueles relacionados à identificação, avaliação e controle dos riscos ambientais.

Os resultados encontrados nesta pesquisa em relação à CIPA são semelhantes aos encontrados por Lacerda et al. (2005) em industrias alimentícias, no qual se identificou a falta de uma atuação efetiva da Comissão, dificultando o atendimento da compatibilização permanente do trabalho com a preservação da saúde dos trabalhadores. Ressalta-se que a CIPA é de total relevância no que se diz respeito às condições de riscos no ambiente de trabalho, sendo responsável por observar, relatar e solicitar medidas para redução, eliminação ou neutralização dos mesmos.

Uma dessas medidas é a elaboração do mapa de risco. A NR-5 (BRASIL, 1999) recomenda que este deva ser elaborado pela CIPA. Na sua confecção devem ser ouvidos os trabalhadores de todos os setores do estabelecimento e com a colaboração do SESMT, quando houver necessária composição. Sendo indispensável, a participação das pessoas expostas ao risco no dia-a-dia. Através de sua elaboração são identificados os diversos fatores capazes de acarretar riscos à saúde do trabalhador e acidentes e doenças de trabalho, indicando de forma prática e clara os riscos envolvidos no ambiente de trabalho, estimulando os trabalhadores quanto à utilização de práticas de prevenção. Tinoco, Brito e Lima (2012) ressaltam a responsabilidade legal, onde a falta de elaboração e afixação dos mapas de riscos nos locais de trabalho pode acarretar em multas elevadas. Essa multa é aplicada em casos extremos, quando fica evidenciada a posição do empregador em fraudar a lei ou resistir à fiscalização.

No que refere a equipamentos de proteção individual, Lacerda et al. (2005), semelhantemente a esta pesquisa, observou índices sensivelmente elevados de ruídos no processo produtivo de uma industria de alimentos, onde os colaboradores utilizavam protetores auriculares, porém sem a comprovação de sua eficácia. Em relação à Empresa $X$, ainda inexistem EPIs para o risco químico, contados na NR-6 (BRASIL, 2001), em que se ressalta que para este caso a utilização de avental, luvas, proteção ocular, bem como máscara para a proteção respiratória seriam ideais.

A Empresa $X$ pode ter locais de insalubridade, em que se faz importante a realização da medição do nível de ruído, a fim de neutralizá-lo ou eliminá-lo, através 
das medidas adequadas. Faz-se importante a adoção de programas que tenham por objetivo prevenir a instalação ou evolução das perdas auditivas nos trabalhadores. Almeida et al. (2000) analisou as características da perda auditiva ocupacional provocada por ruído, onde trabalhadores expostos apresentaram limiares audiométricos altamente desfavoráveis quando comparados a uma população nãoexposta. Miranda et al. (1998) reforça que deve existir o monitoramento dos trabalhadores expostos aos ruídos, a medição periódica dos níveis de pressão sonora dos ambientes, criação de medidas de proteção coletivas, bem como individuais.

O PCMSO, segundo a NR-7 (BRASIL, 1994), tem caráter de prevenção, rastreamento e diagnóstico precoce dos agravos à saúde do trabalhador, constatando casos de doenças profissionais ou danos irreversíveis à saúde do trabalhador. É diretamente ligado ao SESMT, já que o empregador deve indicar dentre os médicos deste Serviço, um coordenador responsável pela execução do Programa. $O$ dimensionamento do SESMT para a Empresa $X$ desobriga $O$ mantimento de um médico, de acordo com a NR-4 (BRASIL, 1983). Neste caso, o empregador deve indicar um médico do trabalho, empregado ou não na empresa, para coordenar o PCMSO. Caberá a este médico desenvolver o Programa conforme recomendações da NR-7, realizando exames médicos; encarregando profissionais familiarizados com os princípios da patologia ocupacional, condições e riscos a que está exposto o trabalhador a ser examinado; fazendo as avaliações pertinentes; entre outros, a fim de garantir a saúde dos trabalhadores.

A NR-9 estabelece a obrigatoriedade, por parte dos empregadores, da elaboração do PPRA, que tem por objetivo a preservação da saúde e integridade dos trabalhadores, através da antecipação, reconhecimento, avaliação e controle dos riscos físicos, biológicos e químicos que venham a existir no ambiente de trabalho (BRASIL, 1994). Mesmo sendo de caráter de obrigatoriedade por parte de todos os empregadores $\mathrm{e}$ instituições que admitam trabalhadores como empregados, a Empresa X não possui tal Programa. Oliveira (2003) enfatiza que muitas organizações agem da mesma forma, em que em função da cultura dominante na maioria delas, os programas de segurança e saúde no trabalho são concebidos e orientados apenas para o atendimento à legislação que dispõe sobre a matéria. Entretanto, as empresas que desenvolvem seus programas pensando Revista Produção Online, Florianópolis, SC, v. 16, n. 2, p. 678-704, abr./jun. 2016. 
dessa forma, possuem um baixo desempenho em segurança privilegiando situações de risco que se apresentam em franco desacordo com a Lei.

Em relação à importância da adoção desses programas que promovem a segurança e saúde no trabalho, Oliveira (2003) ressalta que entre outras vantagens, há o ganho de não ser preciso desenvolver ações em duplicidade para abordar sobre o mesmo conteúdo, que são os aspectos produtivos. Sendo a maior vantagem, a possibilidade de convencer os trabalhadores de que para fazer segurança não é necessário desenvolver ações específicas para tal, basta incluir essa preocupação nos procedimentos de trabalho e transformá-la em ações concretas que possam ser avaliadas e medidas.

Em relação aos riscos de acidentes, recomenda-se à Empresa $X$, a aquisição de novos equipamentos que além de oferecer segurança através de sensores e dispositivos, atenda aos aspectos ergonômicos, a fim de garantir a saúde e integridade física dos colaboradores, remetendo a diminuição dos tempos improdutivos com paradas para reparo. Vale salientar a obrigação de acessos permanentes ou plataformas móveis que possuam estabilidade e ofereçam segurança para o colaborador.

Outro fator importante envolvendo os maquinários são as sinalizações em torno deles, visto que é de extrema importância para a segurança dos que circulam pela empresa que as áreas estejam devidamente demarcadas conforme recomendado pela NR-26 (BRASIL, 2011). Recomenda-se a inserção da sinalização de segurança para advertir aos colaboradores e a terceiros sobre os riscos a que estão expostos em todas as linhas de produção e equipamentos. Esta sinalização compreende cores, símbolos, inscrições, sinais luminosos ou sonoros que ofereçam eficácia, devendo seguir os padrões estabelecidos pelas normas vigentes.

Em relação à ergonomia, recomendam-se ao empregador da Empresa $X$ que haja a adaptação do ambiente, equipamentos e das diversas tarefas desenvolvidas no ambiente de trabalho, a fim de oferecer conforto aos colaboradores. Não deve ser exigido nem admitido o transporte manual de cargas por um trabalhador cujo peso seja suscetível de comprometer sua saúde ou segurança. Recomenda-se a compra de carrinhos de mão e empilhadeiras para assessorar os colaboradores em suas atividades, bem como a realização de treinamento ou oferta de instruções satisfatórias quanto aos métodos de trabalho que deverão ser utilizados pelos Revista Produção Online, Florianópolis, SC, v. 16, n. 2, p. 678-704, abr.jun. 2016. 
trabalhadores com o intuito de prevenir acidentes e salvaguardar sua saúde. A troca das cadeiras do setor administrativo e de toda a linha de produção por cadeiras com regulagem e que ofereçam conforto aos colaboradores é indispensável.

Dul e Weerdmeester (2004) ressaltam os princípios mais importantes da biomecânica para a ergonomia e ressaltam que as articulações devem ocupar uma posição neutra; conservar pesos próximos ao corpo; evitar curvar-se para frente; evitar inclinar a cabeça; evitar torções de tronco e movimentos bruscos que produzem picos de tensão; alternar posturas e movimentos; restringir a duração do esforço muscular contínuo; prevenir a exaustão muscular e opção por pausas curtas e frequentes.

A ginástica laboral pode ser adotada pela Empresa $X$ como meio de auxiliar na produtividade, prevenindo lesões tais como LER/DORT, minimizando o processo de fadiga em trabalhos monótonos e repetitivos, entre outros. Marques e Liberali (2011) enfatizam que a ginástica laboral é um exercício físico eficaz para prevenir doenças relacionadas ao trabalho e quando bem direcionado, utilizando-se, sobretudo bom senso, associado ao conhecimento científico, caracterizando-se o trabalhador como um todo, ele será eficaz.

Problemas encontrados na Empresa $X$ em relação à proteção contra incêndios, também foram encontrados por Lacerda et al. (2005), onde recomenda-se a inspeção do local em relação à quantidade de extintores, observando a distância mínima a ser percorrida, bem como a adequação do local às normas vigentes quanto à localização, sinalização e prazos de validade dos extintores, a fim da rápida localização e fácil utilização destes em caso de incêndio.

Como limitação dessa pesquisa, destaca-se a dificuldade de lidar com a questão de segurança e saúde dos trabalhadores, remetendo a dificuldade na obtenção de informações. Isso nos leva a afirmar que é pouco provável que os trabalhadores da Empresa $X$ vislumbrem a segurança do trabalho como valor agregado do local de trabalho, já que não existem programas de segurança e saúde implementados no ambiente produtivo. Isso demonstra que a participação dos trabalhadores nos programas de segurança e saúde do trabalho está diretamente ligada à cultura da empresa e às ações que ela desenvolve. Num ambiente dessa natureza, dificilmente os colaboradores associam a segurança à promoção da qualidade de vida ou conforto ao próprio trabalho, diferentemente das empresas em 
que os programas de segurança do trabalho são partes integrantes dos processos produtivos e da cultura da empresa.

O trabalho poderá servir de subsídio para outros estudos em segurança do trabalho em indústrias alimentícias, contribuindo para o diagnóstico situacional e a implementação de medidas preventivas para a promoção da saúde do trabalhador.

\section{CONSIDERAÇÕES}

Através da aplicação do checklist foi possível identificar os diversos riscos a que os trabalhadores estão expostos. A partir da avaliação destes ricos é possível fazer a adoção das medidas de controle. As recomendações feitas à indústria estudada se encontram no Quadro 3, nem todas as medidas são simples, porém podem ser eficazes.

Quadro 3 - Recomendações aplicáveis
\begin{tabular}{|c|l|}
\hline NR & Recomendações \\
\hline 4 & Implantar o SESMT e contratar um técnico de segurança do trabalho \\
\hline 5 & Cumprir as atribuições quanto à CIPA e elaborar do mapa de risco \\
\hline 6 & Oferecer EPI adequado e realizar palestras para conscientização sobre seu uso \\
\hline 7 & Implantar PCMSO e indicar um médico do trabalho para coordenar o Programa \\
\hline 9 & Elaborar o PPRA \\
\hline 12 & $\begin{array}{l}\text { Limitar com demarcações as áreas de equipamentos, circulação de pessoas e } \\
\text { armazenamento de materiais em utilização no processo; adquirir ou adequar } \\
\text { equipamentos com proteção fixas, móveis e com sensores de segurança; adequar } \\
\text { equipamento com acessos permanentes ou plataformas móveis; inserir sinalização de } \\
\text { segurança quanto ao local e equipamentos }\end{array}$ \\
\hline 15 & Medir insalubridade quanto aos ruídos \\
\hline 17 & $\begin{array}{l}\text { Comprar carrinhos de mão e empilhadeiras; trocar cadeiras das linhas de produção; } \\
\text { oferecer adaptações para os que realizam trabalhos administrativos; elaborar de ginástica } \\
\text { laboral; oferecer treinamento ergonômico }\end{array}$ \\
\hline 23 & Inspecionar a recarga, quantidade, localização e sinalização dos extintores \\
\hline
\end{tabular}

As propostas referidas a Empresa $X$, visam garantir que 0 ambiente de trabalho seja projetado para a minimização dos riscos à saúde e segurança dos trabalhadores. As modificações com os aspectos aqui apresentados atendem às exigências legais trabalhistas e vão de encontro com o objetivo de empresas que consideram o bem-estar do trabalhador como primordial. Com a adoção dessas medidas, doenças e acidentes podem ser evitados, contribuindo para um ambiente de trabalho mais seguro e saudável para todos. 


\section{REFERÊNCIAS}

ALMEIDA, S. I. C. de; ALBERNAZ, P. L. M.; ZAIA, P. A.; XAVIER, O. G.; KARAZAWA, E. H. I. História natural da perda auditiva ocupacional provocada por ruído. Rev. Assoc. Med.

Bras., São Paulo, v. 46, n. 2, 2000.

BRASIL. Lei no 6.514, de 22 de dezembro de 1977. Altera o Capítulo V do Titulo II da Consolidação das Leis do Trabalho, relativo a segurança e medicina do trabalho e dá outras providências. Diário Oficial da República Federativa do Brasil, Brasília, DF, 22 dez. 1977.

BRASIL. Ministério do Trabalho e Emprego. Classificação Brasileira de Ocupações CBO, 2002. Brasília, DF: Ministério do Trabalho e Emprego, 2002. Disponível em: <http://www.mtecbo.gov.br/cbosite/pages/home.jsf>. Acesso em: 10 mar. 2015.

BRASIL. Ministério do Trabalho e Emprego. Portaria n 33, de 27 de outubro de 1983. NR-4 - Serviços Especializados em Engenharia de Segurança e em Medicina do Trabalho SESMT, Brasília, DF, 31 out. 1983.

BRASIL. Ministério do Trabalho e Emprego. Portaria n 8, de 23 de fevereiro de 1999. NR-5 - Comissão Interna de Prevenção de Acidentes - CIPA, Brasília, DF, 24 fev. 1999.

BRASIL. Ministério do Trabalho e Emprego. Portaria $n^{\circ}$ 25, de 15 de outubro de 2001. NR-6 - Equipamento de Proteção Individual - EPI, Brasília, DF, 17 out. 2001.

BRASIL. Ministério do Trabalho e Emprego. Portaria $n^{\circ}$ 24, de 29 de dezembro de 1994. NR-7 - Programa de Controle Médico de Saúde Ocupacional - PCMSO, Brasília, DF, 30 dez. 1994.

BRASIL. Ministério do Trabalho e Emprego. Portaria n 12, de 06 de junho de 1983. NR-8 Edificações, Brasília, DF, 14 jun. 1983.

BRASIL. Ministério do Trabalho e Emprego. Portaria $n^{\circ}$ 25, de 29 de dezembro de 1994. NR-9 - Programa de Prevenção de Riscos Ambientais - PPRA, Brasília, DF, 30 dez. 1994.

BRASIL. Ministério do Trabalho e Emprego. Portaria 197, de 17 de dezembro de 2010. NR12 - Segurança no trabalho em máquinas e equipamentos, Brasília, DF, 24 dez. 2010.

BRASIL. Ministério do Trabalho e Emprego. Portaria $n^{\circ}$ 12, de 06 de junho de 1983. NR-14 Fornos, Brasília, DF, 06 jun. 1983.

BRASIL. Ministério do Trabalho e Emprego. Portaria $n^{\circ} 3.214$, de 08 de junho de 1978. NR15 - Atividades e operações insalubres, Brasília, DF, 06 jul. 1978.

BRASIL. Ministério do Trabalho e Emprego. Portaria $n^{\circ}$ 3.751, de 23 de novembro de 1990. NR-17 - Ergonomia, Brasília, DF, 26 nov. 1990.

BRASIL. Ministério do Trabalho e Emprego. Portaria 221, de 06 de maio de 2011. NR-23 Proteção contra incêndios, Brasília, DF, 10 mai. 2011.

BRASIL. Ministério do Trabalho e Emprego. Portaria $n^{\circ}$ 229, de 24 de maio de 2011. NR-26 - Sinalização de segurança, Brasília, DF, 27 mai. 2011. 
BRASIL. Secretaria de Vigilância Sanitária do Ministério da Saúde. Portaria nํ326, de 30 de julho de 1997. Regulamento Técnico sobre Condições Higiênico-Sanitárias e de Boas Práticas de Fabricação para Estabelecimentos Produtores/ Industrializadores de Alimentos. Diário Oficial da República Federativa do Brasil, Brasília, DF, 30 jul. 1997.

CARPES JR., W. P.; SELL, I. O produto como causador de acidentes. Revista Produção online, v.4, n.2, 2003.

DUL, J.; WEERDMEESTER, B. Ergonomia Prática. São Paulo: Edgar Blucher, 2004.

HEINRICH, H. W. Industrial accident prevention: a scientific approach. New York: Mac Graw Hill, 1959.

LACERDA, C de A.; CHAGAS, C. E. P.; BARBOSA, C. C.; CABRERA, J. V. D.; FARIAS J. $V$. de. Auditoria de segurança e saúde do trabalho em uma indústria de alimentos e bebidas. Revista Gestão Industrial, v.1, n.2, p.46-56, 2005. http://dx.doi.org/10.3895/S1808$\underline{04482005000200004}$

MAGNANO, C.; DOMINGOS, L. M. G.; SANTOS, P. R. dos; CARVALHO, E. C.; NORONHA, N. H. Notices for hiring offshore security and medical professionals: a documental analysis.

Online Brazilian Journal of Nursing, v.12, n.3, p. 555-564, 2013.

MARQUES, H. S.; LIBERALI, R. Indicadores subjetivos de saúde e qualidade de vida em trabalhadores submetidos a programa de ginástica laboral. Revista Brasileira de Prescrição e Fisiologia do Exercício, v.5, n.28, p. 335-346, 2011.

MENDES, J. M. R.; WUNSCH, D.S. Elementos para uma nova cultura em segurança e saúde no trabalho. Revista Brasileira de Saúde Ocupacional, São Paulo, v. 32 (115), p. 153-163, 2007. http://dx.doi.org/10.1590/S0303-76572007000100014

MENEZES, M. de L. A.; SANTOS, I. J. A. L. Avaliação das condições de trabalho no setor industrial: uma abordagem centrada na ergonomia física e organizacional. Revista Ação Ergonômica, v.9, n.2, p. 67-85, 2014.

MINISTÉRIO DA PREVIDÊNCIA SOCIAL. Anuário Estatístico da Previdência Social. Brasília, 2012. Disponível em: <http://www.previdencia.gov.br/wpcontent/uploads/2013/05/AEPS 2012.pdf>. Acesso em: 02 abr. 2014.

MIRANDA, C. R.; DIAS, C. R.; PENA, P. G. L.; NOBRE, L. C. C.; AQUINO, R. Perda auditiva induzida pelo ruído em trabalhadores industriais da região metropolitana de Salvador, Bahia. Informe Epidemiológico do Sus, Brasília, v.7, n.1, p. 87-94, 1998.

http://scielo.iec.pa.gov.br/scielo.php?pid=S0104-16731998000100005\&script=sci_arttext

OLIVEIRA, J. C. de. Segurança e saúde no trabalho: uma questão mal compreendida.

Revista São Paulo em Perspectiva, São Paulo, v.17 n.2, 2003.

QUELHAS, O. L. G.; ALVES, M. S.; FILARDO, P. S. As práticas da gestão da segurança em obras de pequeno porte: integração com os conceitos de sustentabilidade. Revista

Produção online, v.4, n.2, 2003.

RODRIGUES, L. B.; SANTANA, N. B.; BONOMO, R. C. F.; SILVA, L. B. apreciação ergonômica do processo de produção de queijos em indústrias de laticínios. Revista Produção online, v.8, n.1, 2008. 
TINOCO, H. C.; BRITO, M. M.; LIMA, G. B. A. Influência dos stakeholders no desenvolvimento do mapa de risco nas organizações. Relatórios de pesquisa em engenharia de produção, v.12, n.6, p. 69-86, 2012.

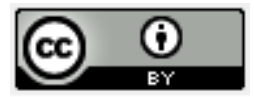

Artigo recebido em 10/06/2015 e aceito para publicação em 19/04/2016

DOI: $\underline{\text { http://dx.doi.org/ 10.14488/1676-1901.v16i2.2063 }}$ 


\section{APÊNDICE}

Checklist para avaliação de não conformidades

\begin{tabular}{|c|c|c|c|c|c|}
\hline NR & Pergunta & Sim & Não & $N / A^{*}$ & Observações \\
\hline \multirow{2}{*}{4} & $\begin{array}{l}\text { 1. Existe Serviço Especializado em Engenharia de } \\
\text { Segurança e em Medicina do Trabalho (SESMT)? }\end{array}$ & & & & \\
\hline & $\begin{array}{lllll}1.1 \mathrm{O} \text { dimensionamento do } & \text { SESMT obedece ao } \\
\text { estabelecido pela NR-4? }\end{array}$ & & & & \\
\hline \multirow{6}{*}{5} & $\begin{array}{l}\text { 2. Existe a comissão interna de prevenção de acidentes } \\
\text { (CIPA) estabelecida normalmente? }\end{array}$ & & & & \\
\hline & $\begin{array}{l}2.1 \text { A CIPA cumpre o que é estabelecido pela NR-5 em } \\
\text { relação à sua organização? }\end{array}$ & & & & \\
\hline & $\begin{array}{l}2.2 \text { A CIPA cumpre o que é estabelecido pela NR-5 em } \\
\text { relação às suas atribuições? }\end{array}$ & & & & \\
\hline & $\begin{array}{l}2.3 \text { A CIPA cumpre o que é estabelecido pela NR-5 em } \\
\text { relação ao seu funcionamento? }\end{array}$ & & & & \\
\hline & $\begin{array}{l}2.4 \text { A CIPA cumpre o que é estabelecido pela NR-5 em } \\
\text { relação ao treinamento? }\end{array}$ & & & & \\
\hline & $\begin{array}{l}2.5 \text { A CIPA cumpre o que é estabelecido pela NR-5 em } \\
\text { relação ao processo eleitoral? }\end{array}$ & & & & \\
\hline \multirow{3}{*}{6} & $\begin{array}{l}\text { 3. A Empresa forneceu aos empregados, gratuitamente, o } \\
\text { Equipamento de Proteção Individual (EPI) adequado ao } \\
\text { risco, em perfeito estado de conservação e funcionamento? }\end{array}$ & & & & \\
\hline & 3.1 Os funcionários estão fazendo o uso correto do EPI? & & & & \\
\hline & $\begin{array}{l}3.2 \text { Todo funcionário recebeu treinamento de uso e } \\
\text { conservação dos EPIs? }\end{array}$ & & & & \\
\hline 7 & $\begin{array}{l}\text { 4. Existe Programa de Controle Médico de Saúde } \\
\text { Ocupacional (PCMSO)? }\end{array}$ & & & & \\
\hline \multirow{5}{*}{8} & 5. Os pisos estão desnivelados ou salientes? & & & & \\
\hline & $\begin{array}{l}\text { 5.1 As rampas ou escadas fixas estão em bom estado de } \\
\text { conservação? }\end{array}$ & & & & \\
\hline & $\begin{array}{l}5.2 \text { Os guarda-corpos tem } 0,90 \mathrm{~m} \text { de altura no mínimo a } \\
\text { contar de nível do piso? }\end{array}$ & & & & \\
\hline & 5.3 Há problemas de pisos de rampas escorregadias? & & & & \\
\hline & $\begin{array}{l}5.4 \text { As coberturas dos locais possuem proteção contra } \\
\text { chuvas e evitam insolação excessiva? }\end{array}$ & & & & \\
\hline \multirow{4}{*}{9} & $\begin{array}{l}6 \text { Existe o Programa de Prevenção de Riscos Ambientais } \\
\text { (PPRA)? }\end{array}$ & & & & \\
\hline & 6.1 Os trabalhadores estão expostos a agentes físicos? & & & & \\
\hline & 6.2 Os trabalhadores estão expostos agentes biológicos? & & & & \\
\hline & 6.3 Os trabalhadores estão expostos a agentes químicos? & & & & \\
\hline \multirow{6}{*}{12} & $\begin{array}{l}\text { 7. Nos locais de instalação de máquinas e equipamento, as } \\
\text { áreas de circulação estão demarcadas? }\end{array}$ & & & & \\
\hline & $\begin{array}{l}\text { 7.1 Os materiais em utilização no processo produtivo estão } \\
\text { em áreas específicas de armazenamento, devidamente } \\
\text { demarcados com faixas na cor indicada pela norma? }\end{array}$ & & & & \\
\hline & $\begin{array}{l}\text { 7.2 As áreas de circulação e os espaços em torno de } \\
\text { máquinas e equipamentos estão de forma em que o } \\
\text { material e os trabalhadores possa se movimentar com } \\
\text { segurança? }\end{array}$ & & & & \\
\hline & $\begin{array}{l}\text { 7.3 As instalações e dispositivos elétricos estão em bom } \\
\text { estado de conservação? }\end{array}$ & & & & \\
\hline & $\begin{array}{l}7.4 \text { Os dispositivos possuem sinalização e identificação } \\
\text { quanto ao perigo de choque elétrico e restrição de acesso? }\end{array}$ & & & & \\
\hline & 7.5 As máquinas e equipamentos possuem sistema de & & & & \\
\hline
\end{tabular}

Revista Produção Online, Florianópolis, SC, v. 16, n. 2, p. 678-704, abr./jun. 2016. 
segurança, tais como proteções fixas, proteções móveis e dispositivos de segurança interligados?

7.6 As máquinas e equipamentos possuem dispositivos de parada de emergência?

7.7 As máquinas e equipamentos possuem sensores de segurança?

7.8 As máquinas e equipamentos foram projetados e construídos de modo que atendam aos aspectos ergonômicos descritos na norma?

7.9 As máquinas e equipamentos dispõem de dispositivos de acionamento com fácil e seguro acesso ao colaborador?

7.9.1 Esses dispositivos podem ser acionados por outra pessoa em caso de emergência?

7.10 Todas as máquinas e equipamentos têm proteção?

7.11 As máquinas e equipamentos possuem chave geral?

7.12 Existe sinal de alarme para acionamento ou desligamento simultâneo de um conjunto de máquinas?

7.13 As transmissões de força das máquinas e equipamentos estão enclausurados dentro de suas estruturas ou devidamente isolados por proteções?

7.14 As máquinas e equipamentos estão aterrados eletricamente?

7.15 Circulam pessoas não autorizadas nas áreas de trabalho com máquinas e equipamentos?

8. Os fornos são revestidos com material refratário de

forma que o calor não ultrapasse os limites de tolerância?

8.1 Eles são dotados de chaminés, de modo que haja a livre saída dos gases queimados?

15 9. O local é insalubre?

9.1 Há necessidade da medição do agente?

17 10. Há transporte manual de carga no local?

10.1 O peso transportado pode comprometer a saúde do trabalhador?

10.1.1 Há meios mecânicos para a realização desta tarefa?

10.2 Para trabalho manual sentado, as bancadas, mesas e escrivaninhas proporcionam ao trabalhador condições de

17 boa postura, visualização e operação?

10.3 Para atividades realizadas de pé, existem assentos para descanso em locais que possam ser utilizados por todos os trabalhadores durante as pausas?

10.4 Nos escritórios existem altos níveis de ruído?

10.5 A iluminação do local de trabalho é adequada?

110 local possui extintores de combate a incêndio?

11.1 Os extintores estão com seu prazo de recarga em dia?

11.2 Os extintores estão em locais de fácil visualização, devidamente sinalizados e desobstruídos?

2311.3 O local possui dispositivo de alarmes para incêndio?

11.4 O local possui saídas suficientes, de modo que os que se encontrem nesses locais possam abandoná-los com rapidez e segurança?

11.4.1 Essas saídas estão devidamente sinalizadas?

*Não se aplica 